\title{
Interdisciplinary education: a learning method for a sustainable model of housing
}

\author{
V. H. Ardila, L. F. Lalinde Castrillón, M. Rodriguez Velazquez \\ \& A. Villa Ortega \\ Universidad Pontificia Bolivariana, Colombia
}

\begin{abstract}
The Solar Decathlon is the international competition of construction of sustainable housing most important in the world. It convokes universities from many countries to present models of housing, which are very efficient with water, energy and other resources.

This competition was created by the US Department of Energy and has been taking place for 14 years in different cities around the world. This year, the event was carried out for the first time in Latin America, specifically in Cali, Colombia.

In this version, new components and conditions to the housing design appear; they must be consequent to the real life in the Latin America tropical context.

The UPB (Universidad Pontificia Bolivariana) decided to conform an interdisciplinary team in order to participate in SSLC 2015. With students and teachers from 8 different faculties, the project was developed in agreement with competition rules, academic requirements for students and the guidelines of sustainable design.

The results that have been obtained until now are very positive in several aspects:

- The object of the contest, what is the design of a sustainable housing model (which will be developed in a future document)

- The academic and educational experience through the interdisciplinary and collaborative work.

In this text, we will focus on the matter of educational experience. We understand this opportunity is a pilot project. This project has allowed us, students and teachers, to understand that to obtain a project which is really sustainable, it is
\end{abstract}


necessary to open our minds and comprehend the reality in a more holistic and integrated manner.

Keywords: education, interdisciplinary, transdisciplinary, multidisciplinary, experimental workshop, job training, teamwork, cooperation.

\section{Introduction}

The Solar Decathlon is a competition for students. It is one of the most important international contests of design and construction of sustainable housing in the world.

For the first time, it will be developed in Latin America, specifically in Cali, Colombia.

This competition evaluates ten different aspects of the housing projects:

- Architecture;

- Engineering and construction;

- Energy efficiency;

- Energy consumption;

- Comfort;

- Sustainability;

- Functioning;

- Marketing and communication;

- Urban design and affordability;

- Innovation.

This version of the Solar Decathlon was developed from October 2014 until December 2015. During the year, there are several key moments when each team send the organization the progress documents of the project. At the end, the finalist teams travel to Cali to build their house prototype.

One of the most important issues is the house must to be built by the students, the competition evaluates the construction process and then, they evaluate the house in operation.

Solar Decathlon asks each team to perform some activities in the house, such as cooking, washing clothes, etc. These activities are performed to measure energy or water consumption. All the houses are constantly monitored for 15 days in order to measure internal conditions, such as temperature, humidity and lighting.

At the end of the competition, there is a winner. The goal is to build a neighborhood (200 houses approx.) with this project.

\section{Basic concepts}

The Universidad Pontificia Bolivariana in Medellín, Colombia decided to conform a team of students and teachers from different professions to participate in SolarDLAC 2015 (named Yarumo UPB), and create an area of academic work for the design of the proposed dwelling.

Other issues located in the academic setting was the need to generate and enrich the educational level of the students involved, introducing as a response the implementation of learning models based on multidisciplinary, interdisciplinary 
and transdisciplinary work. According to Alain Findeli, professor at the School of Industrial Design at the University of Montreal, in its document of Research through Design and Transdisciplinarity: A Tentative Contribution to the Methodology of Design Research [1]; affirms that these issues are fundamental for research and professional work in design.

Although multi, inter and transdisciplinary terms are not precisely the main subject of this document, it is important to outline the terms to articulate the dynamic method by Yarumo's academic work.

Multidisciplinary means non-integrated disciplines, which keep their methods and knowledge of work, but create opportunities for collaborative work. Interdisciplinarity is known as the set of disciplines working together, mixing practices and a common object and transdisciplinarity proposes a scenario where each discipline generates a holistic and interconnected vision to other disciplines.

Yarumo's project, besides the academic setting, has created a space where it currently combines over eight fields of knowledge such as architecture, civil engineering, mechanical engineering, electrical engineering, electronic engineering, chemical engineering, industrial design, graphic design and social and journalistic communication. The team consists of six teachers and 34 students from the university.

The aspect of the multiprofessionality is the main reason to develop a teaching method that could allow the dynamic of a university class to manifest itself with content, techniques and practices. In the case of Yarumo, this starts from the particular disciplines and converge in the generality of the common goal, which is the design and construction of the housing.

\section{Particular experience}

\subsection{Competition requirements}

The competition was created in 2002 by the Department of Energy of the United States and has been replicated in the 2005, 2007, 2009, 2011 and 2013 "Solar Decathlon US"; then it reached an international level with "Solar Decathlon Europe" and "Solar Decathlon China".

In 2015, the first version of Solar Decathlon Latin America and the Caribbean LAC2015, students from different careers participate in creating, building and operating self-sustaining social solutions, run by solar power. The headquarters this time is Colombia.

The Government of Colombia considers that the realization of the Solar Decathlon Latin America and Caribbean SD LAC2015 in the city of Santiago de Cali contributes to the promotion of national strategies based in:

- Efficient Energy Management: sustainable development is not possible without sustainable energy;

- Promotion and Use of Non-Conventional Energy Sources;

- Sustainable Social Housing;

- Research and Development;

(from Solar Decathlon Latin America \& Caribbean 2015 draft rules V.2) [4]. 
The Solar Decathlon 2015 contest has two general goals: social housing and regional relevance.

All aspects are related to the 10 categories to assess. The complete assembly of physical components installed in the Solar Village must be in accordance with the rules, particularly, the achievement of the roles assigned to each decathlete.

Each team is autonomous in deciding if the assigned role coincides with the formation of each student. The integration of multiple professions is recommended to answer during the competition in each of the categories evaluated. The following roles are distinguished (see Table 1):

Table 1: Organization functions.

\begin{tabular}{|l|l|}
\hline Construction Manager & $\begin{array}{l}\text { A decathlete responsible for the planning and } \\
\text { execution of the construction, transport, assembly, and } \\
\text { disassembly of the house. }\end{array}$ \\
\hline Contest Captain & $\begin{array}{l}\text { A decathlete responsible for the team's primary } \\
\text { strategy and coordinator of all measured Contest } \\
\text { Tasks; is also responsible for demonstrating the } \\
\text { compliance of appliances with the Rules. }\end{array}$ \\
\hline Student Team Leader & $\begin{array}{l}\text { A student team member responsible for the } \\
\text { coordination among the team. Ensures that official } \\
\text { communication from the organizers are routed to the } \\
\text { appropriate team member(s). }\end{array}$ \\
\hline $\begin{array}{l}\text { Site Operations } \\
\text { Coordinator }\end{array}$ & $\begin{array}{l}\text { A team member responsible for developing and } \\
\text { enforcing the teams' Site Operations Plan during the } \\
\text { competition phases, assembly and disassembly of the } \\
\text { houses. }\end{array}$ \\
\hline Project Manager & $\begin{array}{l}\text { A decathlete responsible for the planning and } \\
\text { execution of the project. }\end{array}$ \\
\hline Project Engineer & $\begin{array}{l}\text { A decathlete responsible for the engineering design } \\
\text { effort; license not required. }\end{array}$ \\
\hline $\begin{array}{l}\text { Communications } \\
\text { Coordinator }\end{array}$ & $\begin{array}{l}\text { A team member responsible for the team's } \\
\text { communications, for the media and developing of all } \\
\text { communications materials, as well as for updating the } \\
\text { information concerning the Communications activities } \\
\text { through the SD LAC2015 workspace. }\end{array}$ \\
\hline Project Architect & $\begin{array}{l}\text { A decathlete who is responsible for developing and } \\
\text { enforcing the team's Health \& Safety Plan during the } \\
\text { competition phases, assembly and disassembly of the } \\
\text { house. }\end{array}$ \\
\hline $\begin{array}{l}\text { A decathlete collaborating with the organizers' } \\
\text { instrumentation team to develop a plan to } \\
\text { accommodate the equipment used to measure the } \\
\text { performance of the home during the competition. }\end{array}$ \\
$\begin{array}{l}\text { A decathlete responsible for the architectural design } \\
\text { effort; license not required. }\end{array}$ \\
\hline Coordinator
\end{tabular}




\subsection{Disciplinary skills}

The Universidad Pontificia Bolivariana in its educational statements declares the importance of learning models based on multidisciplinary, interdisciplinary and transdisciplinary work. They are important components in the professional education that seeks the development and complementarity of the knowledge, the pedagogic practices, the education purposes and the contextualization of the student work. These components, in order to increase the impact of the proposals at human and social levels (UPB [2]).

Today the different disciplines of knowledge deal with the challenge of getting into an open and globalized society. It is necessary to keep in mind the importance not only of the techniques but also the cultural, political, social and economic dimensions of the present time, of the specific context in which the project is being developed.

In this case, the Solar Decathlon competition is the perfect scenario to let the students get involved with an experience that helps to reinforce the skills which the university is working to attain. Graduates committed to being responsible and ethical with communities. They will have the capacities of guiding their projects in an appropriate way; affordable and sustainable projects for the Colombian and Latin American context.

The Solar Decathlon is a competition for undergraduates, an opportunity to participate in a real professional project, where the prototype (the model of the sustainable house) has to be produced with the actual materials and manufacturing processes. It should be noted that in the academic projects, the results are often shown by scale models. This means that the students can rarely see their results as real and functioning spaces or objects.

The interdisciplinary work, the time invested in the project and the money resources makes of this competition a real learning environment where the students develop the skills to carry out pertinent projects in professional contexts.

These educational purposes from the Universidad Pontificia Bolivariana are guided to get in line with the companies' recruitment new staff needs. Graduates that are being hired are those who can put into practice all their skills in professional projects; projects that require the understanding of the working methods, vocabulary, and the working tools of the different disciplines involved, engineers, architects, designers, and social communicators.

With the interdisciplinary work, team work is reinforced; the students learn to communicate in appropriate ways with their colleagues, in order to be accurate and efficient in the project. A bad understanding between disciplines could generate delays in the project, or lead to take a choice that diverts the primary objectives established in the beginning.

Next to the work between students of different disciplines, there are important contributing processes led by the teachers that permanently advise and follow the development of the project. The interdisciplinary learning works in two interconnected lines: one made by the students and the other by the teachers and advisors with studies in different areas of knowledge. 
In the Yarumo UPB team, the teachers have postgraduate studies in specific subjects that contribute directly to a sustainable housing project: experts in bioclimatic matters, comprehensive neighborhood improvement, structural design, materials and construction processes, furniture design, communications and marketing, waste water management and of course experts in electrical and solar energy, among others.

The learning in this kind of project goes in two ways, the students learn from teachers and their colleagues and the teachers learn from their students and their colleagues as well.

This learning model is a permanent knowledge generator, not only because of the research in the project but also the knowledge acquired as a result of this interdisciplinary experience. The matter this document focuses on and of course one of the UPB education purposes, generates pedagogic experiences that contribute to improving the development of the academic projects.

\subsection{Experimental educational workshop}

For Yarumo UPB, it was necessary to create a methodology based on the multi, inter- and transdisciplinarity

The first step was to identify the skills and knowledge in each discipline according to their expertise. As a consequence, all members were divided into five subgroups in order to respond to the different needs of the main project. Architecture, industrial design, energy, sustainability, communication and marketing were united as one team.

Each multidisciplinary subgroup is made of students of the same discipline or a related one and led by one or two teachers who also share the knowledge, skills and practices of the discipline to lead. Each group was assigned specific tasks based on their knowledge, in order to complete the requisites of the main project in each stage of the process.

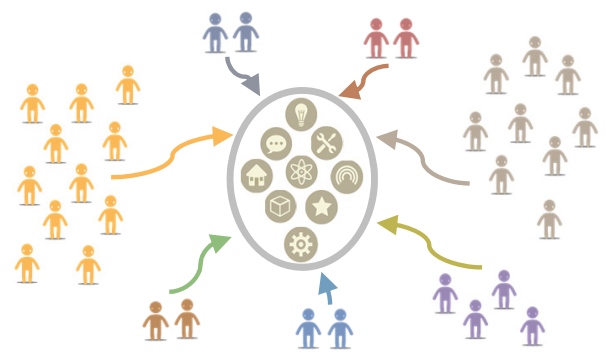

Figure 1: Multidisciplinary work.

Each subject is related to a deliverable for SolarDLAC that allows each area's leader to implement the contents and the teaching practices so all the students can learn and develop each of the jobs from all different areas. 
The interdisciplinary aspect begins to weave into the process of development of the items to be delivered. Although each work item is linked to a subgroup, for the good development of the items, the different disciplines begin to create collaborative links between them spontaneously as in the real needs of the project. The solution is not given by a single discipline of knowledge but rather from all because in a solution different disciplines with a common objective should converge.

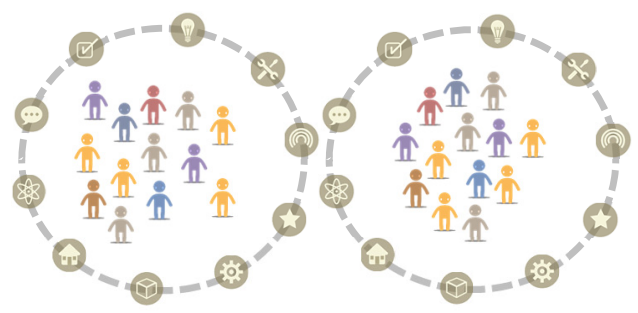

Figure 2: Interdisciplinary work

One example is the creation of a conceptual and visual identity encompassing thought, ideals and equipment statements. The challenge in developing the identity was to create a proposal that will achieve unification of the ideas and thoughts of the interdisciplinary team and respond to the emotional communication of a brand. For this, the starting point was to generate statements about the concept of sustainable housing in Latin America and the Caribbean from the different disciplines that make up the team. From those statements a communication team consolidated a concept, a name and a brand.

The approach of Yarumo's transdisciplinary work is manifested in the creation of spaces of knowledge, discussion and participation of all disciplines, in areas such as bioclimatic, comprehensive neighborhood improvement, electricity and solar energy, social design and design for people, among others. Specific issues that may be particular to one discipline were exposed to all subgroups in order to achieve the particular and general goal of SolarDLAC 2015.

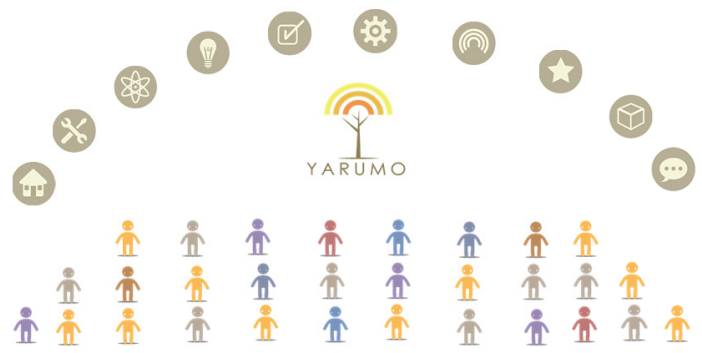

Figure 3: Transdisciplinary work. 


\subsubsection{Conformation of Yarumo UPB team}

The administrative will of the university was a key point in order to implement this workshop. The experience began in October of 2014, when seven faculties of UPB Medellín decided to participate in the competition.

The directives of the faculties agreed to make flexible the different curricula, in order for the students to be able to validate this work by regular academics. Each faculty also appointed teachers who would be responsible for guiding the process of design and construction. Also, they expedited financial resources for participation in the event.

In November 2014, an internal call was opened for students of architecture, industrial design, graphic design, social and journalistic communication and mechanical, electrical, electronic and chemical engineering. Thirty-two students where elected based on their academic profiles.

From that moment we started with a series of academic, investigative, social and commercial activities, which has allowed the team cohesion working as a unit and not as a union of parts.

For students and teachers, this method of work became a great challenge, because it is the first time the university has done something like this in such an explicit way.

It is amazing how students have adapted to work multi, inter, and transdisciplinarily. It is possible to notice their open minds; ready to receive what others, from different disciplines can contribute. All with the common goal that moves to the same direction.

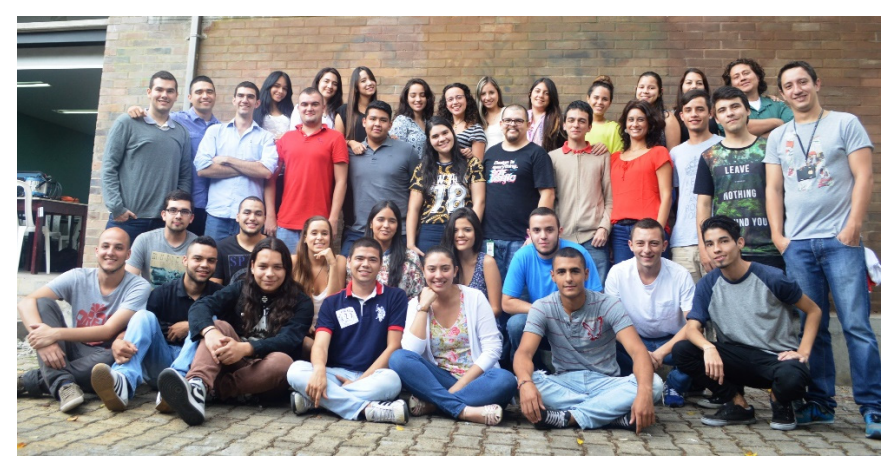

Figure 4: Conformation of Yarumo UPB team.

\subsubsection{Performed activities}

3.3.2.1 Field research The team has made frequent visits to the Yarumito neighborhood, in order to know their environmental characteristics, infrastructure and especially to understand the culture of the community. Therefore, Yarumo team can give an adequate response to the project. 


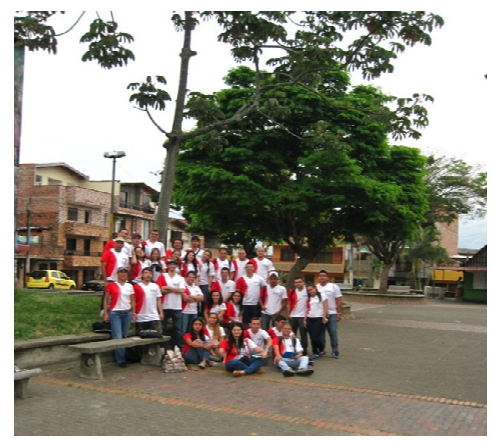

Figure 5: Yarumo UPB team in Yarumito neighborhood.

3.3.2.2 Integrative theoretical seminar An intensive seminar was performed in order that all students understand some of the other disciplines involved in the project. All the students from the seven faculties had to assist in conferences of the following subjects:

- Sustainability;

- Energy efficiency;

- Electrical and electronic systems;

- The domestic space;

- Construction materials;

- Passive design;

- $\quad$ Strategies and methodologies for communication;

- Representations and intercultural.

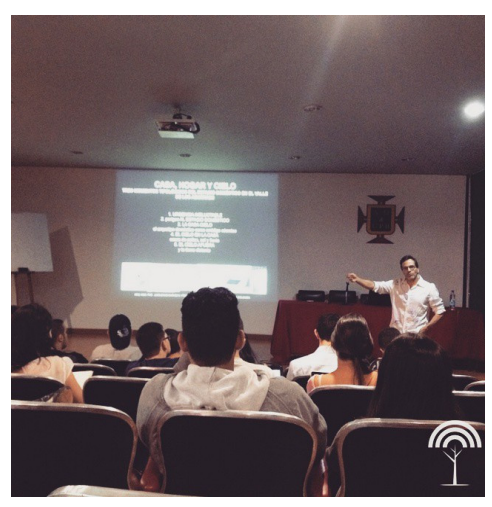

Figure 6: Integrative theoretical seminar.

3.3.2.3 Social integration activities At the beginning, team members were unknown to each other. Social and teamwork activities were conducted, which helped unite the group and create bonds of friendship, which was necessary to bring the project to fruition. 


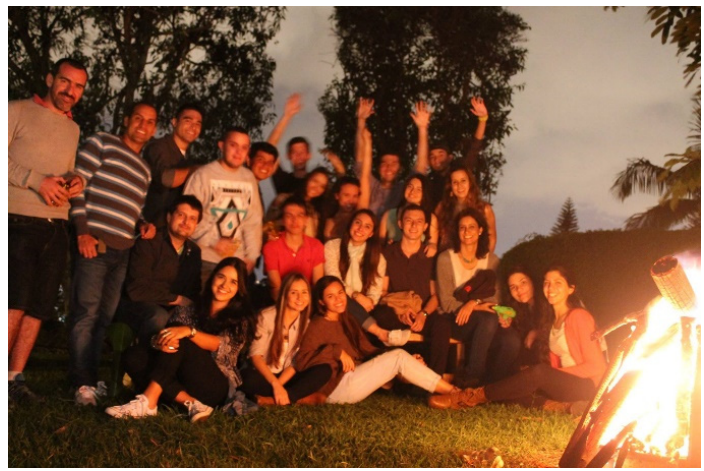

Figure 7: Yarumo UPB social integration.

3.3.2.4 Implementation of a workshop-classroom This is a space that is open permanently - every day; all day. It has been essential for the team, because in it all 32 students can converge to work both the hours designated as mandatory, as in the time they devote to work independently. In this place, there are always people working; small groups of architects, engineers, designers or journalist working together. There is a permanent dialogue and discussion between all disciplines about the project.

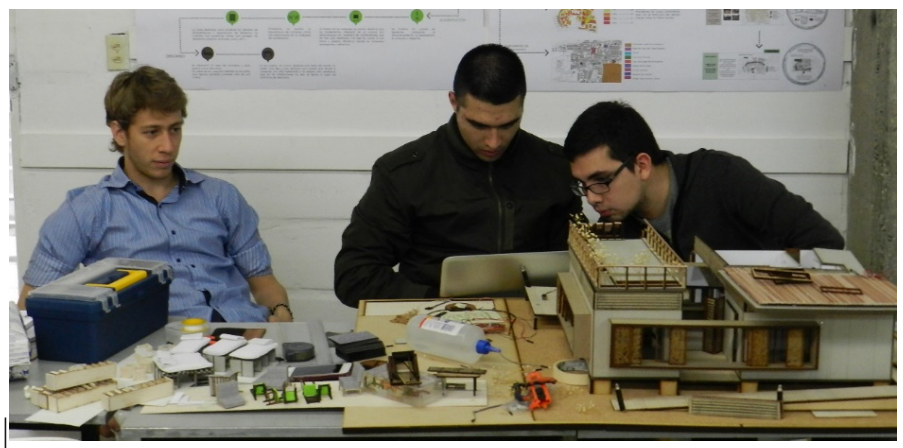

Figure 8: Ongoing work in the workshop-classroom.

3.3.2.5 Relationships with private companies To develop and build the house, we have 9 companies as our sponsors. In addition, students have the opportunity to make their professional practices with them. Yarumo also receive specific training courses by the private companies.

3.3.2.6 Additional training Work at height and First Aid. All students must be trained. Compulsory attendance courses are carried out in partnership with other institutions. 


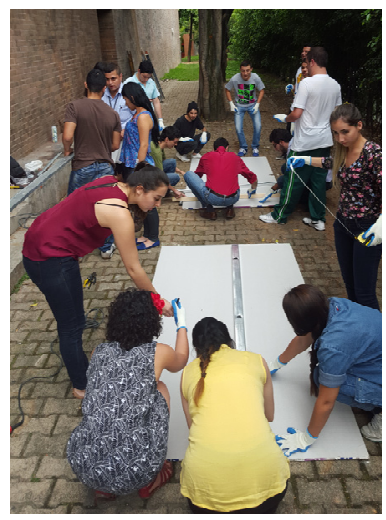

Figure 9: Special training courses.

3.3.2.7 Individual work: specific tasks The Yarumo team is made of persons. That is why every student can and should empower and exploit their individual skills.

3.3.2.8 Interdisciplinary work for urban design The city is the best scenario in which converge all disciplines of knowledge. The integral solutions can only arise from an interdisciplinary group.

3.3.2.9 Mini internal competition for housing prototypes Five sub-teams were formed; each with one or two members of each discipline. Each group must propose their ideal model house. From this competition emerged ideas for houses since the beginning of the project; they took into account the assumptions that each discipline could bring important ideas to the main goal. It was a special challenge for all, but a learning process without precedent.

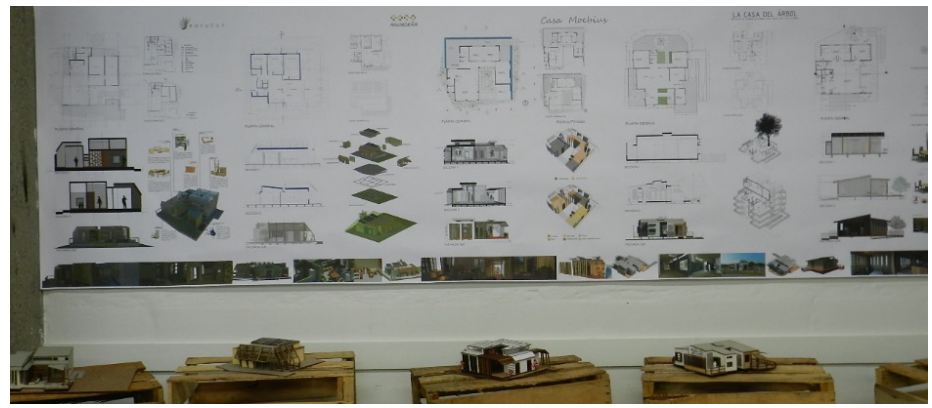

Figure 10: Exhibition of results of mini internal competition.

3.3.2.10 Exhibitions and participation in media All the students from all disciplines know and understand the project in a holistic way, not biased. This has allowed all the integrants to participate in TV and radio shows as well as 
newspaper and social networks. They have been able to communicate the bases and details of the projects and the team strengths.

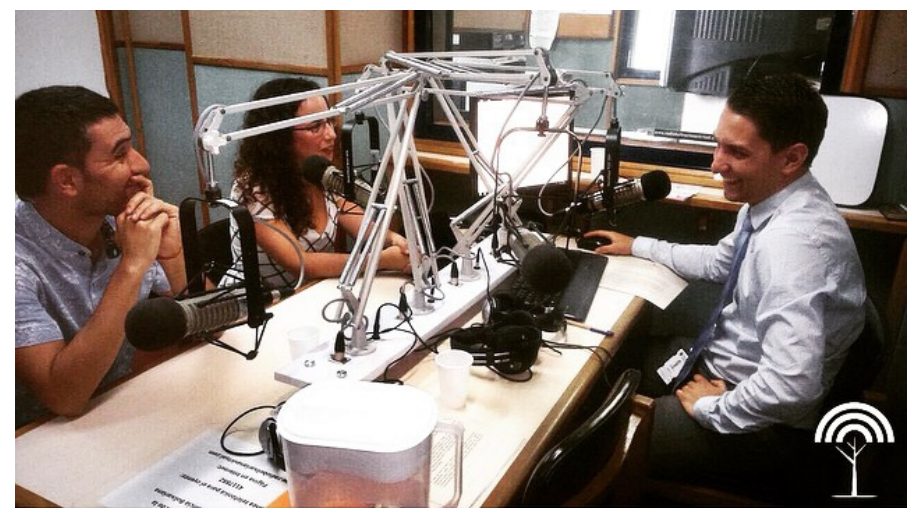

Figure 11: Recording a radio show.

3.3.2.11 Grading work Not to mention that this project is part of an academic process, it must evaluate and score each student's achievements. Teachers evaluate specifically each discipline, even when the review is done together.

3.3.2.12 Multidisciplinary house prototype development The prototype to be built in Cali will be evaluated from many aspects. That is why it is necessary that it is the result of the comprehensive and holistic work of all disciplines.
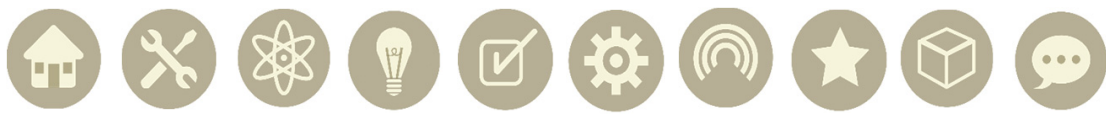

Figure 12: Architecture; engineering and construction; energy efficiency; energy consumption; comfort; sustainability; functioning; marketing and communication; urban design and affordability; innovation.

\subsection{Conclusions: achievements towards sustainability}

Yarumo UPB team through field research, the workshop-classroom and the interaction with private companies, has come to understand the current situation and needs of the Latin American middle class.

In addition, the inter, trans and multidisciplinary work has allowed all the students to commit to work focused on reality and has enabled great achievements that will be fundamental to their professional future.

\subsubsection{Environmental care}

Addressing an existing neighborhood (Barrio Yarumito): they can keep green land within the city. This contributes to the environment as follows: 
- Reduces the "urban heat island effect";

- Keeps green lungs in the city;

- Keeps the ecosystem of the area.

\subsubsection{Correspondence with the reality of a Latin American neighborhood}

The design of the housing comes from the study that is done on the social dynamics of Yarumito neighborhood, which is a mirror of many Latin American neighborhoods.

The Yarumo team proposes:

- Housing of various types;

- Housing with possibilities of expansion (the families grow; their needs change);

- Housing with spaces for production or work from home (the families can obtain livelihoods from their homes).
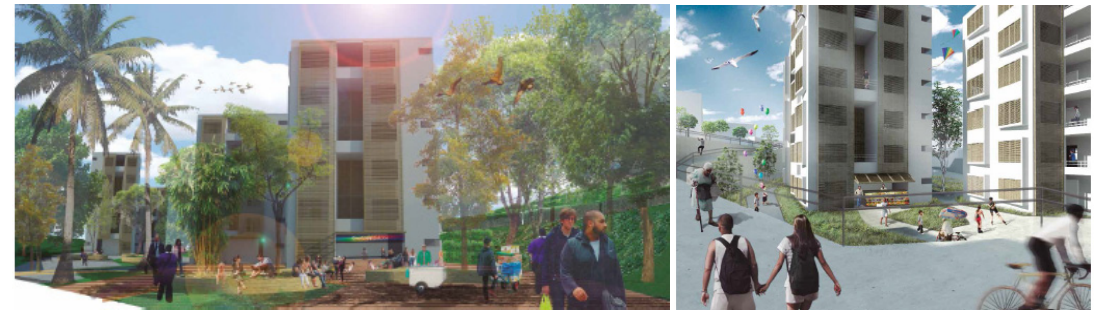

Figure 13: Urban maginariums.

\subsubsection{Urban integration}

The project integrates, coordinates and complements the rest of the existing neighborhood.

\subsubsection{The public space as a major player}

According to one of the most important cultural characteristics of Latin American people, public spaces as natural parks, bikeways and small squares are provided by the project. In these spaces the community can come together to interact in various ways.

\subsubsection{Urban gardens, orchards and community facilities}

It is proposed for the neighborhood a community orchard and garden that contributes to self-sustainability of its inhabitants. Also is designed a building for community services with meeting rooms, nursery, children daycare, and art activities.

\subsubsection{Passive design}

The Yarumo housing buildings are located strategically according with the sun and wind direction. Thus is possible to obtain comfort conditions in the houses without the need to use active systems which use unnecessary energy. 
The houses are designed thinking of the tropical climate. Using the correct orientation, spatial distribution, patios, choice of materials and design of the facades, we achieve that the houses have comfortable indoor weather in a natural and free way.
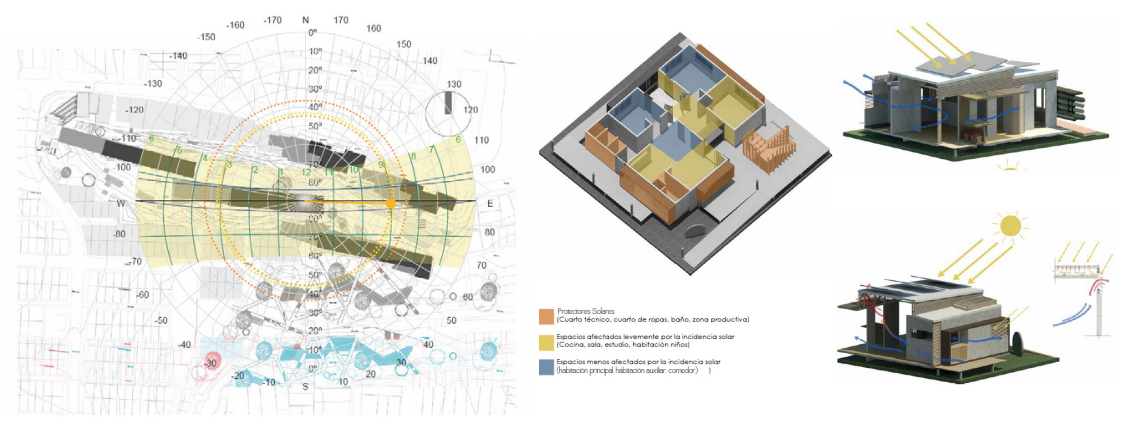

Figure 14: Passive design.

\subsubsection{Productive houses}

Latin American families are constantly seeking to improve their economic conditions and quality of life. Accordingly, Yarumo houses facilitate the flow of the economy by implementing a space for productivity or trade. The productive space not only is good for the family economy but also benefits family cohesion; it allows some family members to remain in the house and at the same time taking care of their children or grandparents, etc.

\subsubsection{Construction efficiency}

Students care about making efficient use of materials through the modulation of all the elements. The prefabricated building system minimizes construction time reducing costs; it also seeks to dispense with additional finishes.

\subsubsection{Energy responsibility}

It designed an installation with photovoltaic panels that can meet the needs of each home. The students understand that for a long time solar energy has been wasted and interpret this project as a great opportunity to focus the world's eyes on cleaner energy sources that contribute to environmental protection. They also perceive that proper design of the energy system not only optimizes resources but the installation is facilitated.

\subsubsection{Reduced environmental impact}

The team has worked to implement production processes that generate the least possible environmental impact by optimizing production time, energy and raw materials for use. Yarumo UPB have also succeeded in raising strategies that provide opportunities to be more accountable to human practices within the home environment, by encouraging users with a more sustainable way of life. 


\subsubsection{Socialization and dissemination}

The students have realized the importance of knowing how to communicate a project. The team has managed to lead conscious actions in pursuit of a collective effort to ensure the care of their surroundings. In the same vein, through social networks and constant management, it has won a large number of people who share that style of seeing the world.

\section{References}

[1] Weekly Colloquium: 'Research through Design and Transdisciplinarity: A Tentative Contribution to the Methodology of Design Research' by Alain Findeli.

[2] Orientaciones para la transformación curricular. Medellín: UPB 2010.

[3] Verlee Williams, Linda. Aprender con todo el cerebro. Ed. Martinez Roca. Barcelona 1986.

[4] Solar Decathlon Latin America \& Caribbean 2015 Draft rules. 